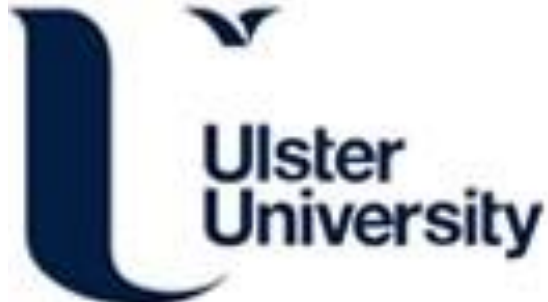

\section{Genetic Polymorphisms and Zinc Status: Implications for Supplementation in Metabolic Diseases}

Virgili, F., Ambra, R., McCormack, J. M., Simpson, L., Ciarapica, D., Barnaba, L., Azzini, E., \& Polito, A. (2018). Genetic Polymorphisms and Zinc Status: Implications for Supplementation in Metabolic Diseases. Current Pharmaceutical Design, 24, 1-13. https://doi.org/10.2174/1381612824666181016155903

Link to publication record in Ulster University Research Portal

\author{
Published in: \\ Current Pharmaceutical Design
}

Publication Status:

Published online: 30/11/2018

DOI:

$10.2174 / 1381612824666181016155903$

\section{Document Version}

Author Accepted version

\section{General rights}

Copyright for the publications made accessible via Ulster University's Research Portal is retained by the author(s) and / or other copyright owners and it is a condition of accessing these publications that users recognise and abide by the legal requirements associated with these rights.

\section{Take down policy}

The Research Portal is Ulster University's institutional repository that provides access to Ulster's research outputs. Every effort has been made to ensure that content in the Research Portal does not infringe any person's rights, or applicable UK laws. If you discover content in the Research Portal that you believe breaches copyright or violates any law, please contact pure-support@ulster.ac.uk. 


\title{
Genetic Polymorphisms and Zinc Status: Implications for Supplementation in Metabolic Diseases
}

Fabio Virgili ${ }^{1}$, Roberto Ambra ${ }^{1}$, Jacqueline McCormack $^{2}$, Elizabeth Ellen Simpson ${ }^{3}$, Donatella Ciarapica ${ }^{1}$, Lorenzo Barnaba ${ }^{1}$, Elena Azzini ${ }^{1}$ and Angela Polito *1

${ }^{1}$ Council for Agricultural Research and Economics (CREA), Research Centre for Food and Nutrition;

${ }^{2}$ Institute of Technology Sligo, Ash Lane, Sligo, Republic of Ireland; ${ }^{3}$ Psychology Research Institute, Ulster University, Coleraine, Northern Ireland

*Address correspondence to this author at the Research Centre for Food and Nutrition- ${ }^{1}$ Council for Agricultural Research and Economics (CREA), Via Ardeatina 546, 00178 Rome, Italy; Tel: 06514941 Fax: 06 51494550;

e-mail: angela.polito@crea.gov.it

\begin{abstract}
Background: Zinc is an essential component for all living organisms, representing the second most abundant trace element, after iron. This element is widely distributed in the tissues of human body where it is involved in the normal growth, reproduction and several biological functions including immunity, energy metabolism and antioxidant processes. Because of its essential role, zinc levels in human body must remain constant, independently of dietary intake fluctuations. The homeostasis of zinc is a well-regulated cellular process and has been reported to be chiefly mediated by the expression and activity of zinc-binding proteins such as metallothioneins and zinc transporters. Genes encoding for these proteins are subjected to genetic variants.
\end{abstract}

Methods: We performed a multi-database electronic search to provide an overview on the relationship between specific polymorphisms (SNP) of genes encoding for metallothioneins and zinc transporters and their relationship with zinc status, immune function and some non-communicable diseases.

Results: A number of SNP are implicated in a range of metabolic disease. Some SNP may affect the impact of zinc supplementation on immune function, diabetes, obesity.

Conclusion: New studies are needed to clarify the interaction between individual genetic profile and zinc status. Moreover, there is a need to a better interaction between the scientific bodies and health professionals to allow better dietary and behavioural recommendations to promote human health, with particular concern to elderly people.

Keywords: Zinc, Genetic Polimorphisms, Metallothionein, Zinc transporters, Immune function, Noncommunicable disease

\section{INTRODUCTION}

Zinc $(\mathrm{Zn})$ is recognised as an essential micronutrient involved in the structural and functional components that underpin a wide range of biological processes involved in cellular metabolism, growth, development, cellular physiology and immune function [1]. To date more than 300 enzymes and 100 transcription factors have been identified to have a requirement of $\mathrm{Zn}$ for their activity. Zn plays a key role as a structural component for the stabilization of the tertiary structure of many proteins, such as transcription factors containing "zinc finger" (ZNF) domains, which interact with a variety of proteins, lipids and nucleic acid. Moreover, as cofactor of numerous enzymes present in animal tissues, it ensures the catalytic activity of six main classes of enzymes including oxidoreductases, transferases, hydrolases, lyases, isomerases and ligases [2, 3].

Because of its essential pleiotropic role, human body needs to maintain constant levels of zinc, independently of dietary intake fluctuations. In humans, the daily turnover corresponds to about $1 \%$ of the total zinc content. Zinc is lost through urine and by the non-avoidable skin and intestinal cell desquamation and hair. In specific harsh conditions, significant amounts can be lost through perspirations and together with occasional loss of fluids during menstruations and ejaculation. The homeostasis is therefore obtained thanks to its daily replacement by the diet and is closely controlled by the intestinal absorption system and excretion through pancreatic and intestinal secretions. The homeostasis of zinc is a well-regulated cellular 
process. In fact, the expression of the membrane conveyors and zinc sequestering proteins varies greatly and rapidly, depending on the intracellular concentration of zinc [4].

The homeostasis of zinc has been reported to be chiefly mediated through the expression and action of zinc binding proteins such as metallothioneins (MTs) and zinc transporters [5, 6]. According to membrane topology data, transporters of zinc have been grouped into two major families:

(a) 10 zinc "exporters" (ZnT1-10) of the SLC305 family, which are associated with lowering of cytoplasmic zinc by transportation of zinc either out of the cell or into intracellular organelles, and

(b) 14 zinc "importers" of the SLC39s family (Zrt (zinc regulated transporter)-like Irt (ironregulated transporter)-like proteins, ZIP 1-14), the activity of which result in increased cytoplasmic zinc [7].

Zinc associated to enzymes and transcription factors accounts for about $90 \%$ of the zinc proteome - indicating the key role of this trace element in the regulation of the processes of catalysis and transcription [6]. MTs are a cysteinerich family of proteins, mainly localized at the level of Golgi apparatus having the capacity to bind either Zinc and other transition elements (Selenium and Copper) or potentially toxic heavy metals such as mercury and arsenic [8]. By binding and releasing zinc, MTs may regulate zinc levels within the body and are involved in $\mathrm{Zn}$ detoxification. Thanks to its protein sequence, rich in cysteines, and its quaternary structure, MTs are able to bind 7 zinc atoms, sequestering them from the surrounding environment, in order to protect the cell from its toxic action [9]. MTs expression is ubiquitous but is particularly high in parenchymal cells of the intestine, pancreas, kidney and liver.

Very few data are available on the molecular mechanisms involved in MTs' and ZnTs' functions. MTs' cellular protection mechanisms were initially shown to involve interaction with antioxidant proteins [10-12]. Then, a role of reactive oxygen species (ROS) [13], antiinflammatory [14], antiapoptotic proteins [15] and of the mitogen-activated protein kinase [16] was reported. More recent findings show an indirect involvement of uncoupling proteins in the MTsdependent attenuation of the free radical-induced cardiac toxicity [17]. With respect to ZnTs, some data is available for $\mathrm{ZnT7}$ that has been shown to upregulate insulin gene expression through MTF1 activation [18] and Irs2 and Akt phosphorylation [19]. MTF1 is believed to act as a buffer influencing the cellular sensitivity to zinc through the modulation of MT and $\mathrm{ZnT}$ expression [20], however, no information is available on the relationships between ZnTs, zinc and MTF1. Similarly, ZnT9 functions as a transcriptional coactivator moving into the nucleus upon activation by hormone stimulation, binding to nuclear receptors complexes to regulate gene transcription [21] and activating Wnt signaling through $\beta$-catenin interaction [22]. However, no information is available on ZnT9 transcriptional activation.

Zinc deficiency has been associated with insufficient dietary intakes or impaired intestinal function in groups of population either aged or suffering of a wide spectrum of different chronic conditions and also related to specific dietary profiles such as vegetarian/vegan [23,24]. Given that there are no specialised storage reserves of zinc within the body, it is necessary to maintain an adequate, regular supply [25]. Specifically, people in developing countries are at particular risk and it has been estimated that globally close to 2 billion people may be zinc deficient [3]. A broad range of clinical manifestations have been associated either to nutritional zinc deficiency or to inherited phenotypes concerning zinc absorption and metabolism. When zinc homeostasis is concerned, several important pathologies have been reported including growth retardation, testicular hypofunction, compromised immune function, oxidative stress, and an increase in the production of inflammatory cytokines [2, 5, 7, 26-28]. Accordingly with the evidence of the association between zinc deficiency or malnutrition and diarrheal disease, zinc supplementation has been used for the treatment and prevention of diarrhoea in infants and children [3,29]. The occurrence of a more marginal zinc deficiency has been observed in vegetarians and vegans and is thought to be the result of the consumption of high levels of zincchelating agents present in cereals, legumes or plant parts. In fact, lignins and phytate, found in these types of foods, have been reported to be able to bind Zinc and counter its absorption therefore reducing its bioavailability [6, 30,31]. It has also been reported that a rise in $\mathrm{Cu}$ to $\mathrm{Zn}$ ratio $(\mathrm{CZr})$ is a common feature associated with a number of agerelated chronic conditions; something which has been postulated to be more dependent on physiological alterations arising with age as opposed to regular nutritional intake $[32,33]$.

Elderly people are a group of population at an increased risk of nutritional disorders owing to a combination of the impact of the ageing on physiological/physical/biochemical capacities, as well as behavioural and dietary factors [24,34]. People aged more than 60-65 years have been 
reported to have intakes of zinc significantly below the recommended intakes, and about $30 \%$ of them has been assessed as "zinc deficient" [6]. This deficiency, is likely to result in impaired immune function and in a significant increase of the risk of a spectrum of degenerative disease [24].

Zinc has low toxicity and is generally considered to be safe even though very high, excessive supplementations can have detrimental consequences possibly due to inadequate absorption of copper [35]. Therefore, numerous zinc supplementation trials have shown a wide range of health benefits, including decrease diarrhoea mortality in children, incidence of infections and immune functions improvement [3639]. Moreover, the efficacy of zinc supplements in boosting health and well-being has been further confirmed by the meta-analysis addressing growth and body weight gain in children [40] and also dealing with the incidence of blindness and the risk of developing age related macular degeneration [41].

Single nucleotide polymorphisms (SNPs) are a common type of genetic variation with high prevalence $(>1 \%)$ among people. Each SNP is characterized by a specific substitution of a single DNA base occurring with high frequency. Overall, population studies conducted by multicentric consortia have recent contributed to the identification of about 60 million SNPs in the human genome [42]. These allelic variants may fall within coding and in non-coding sequences of genes as well or in the intergenic regions (regions between genes). SNPs within a coding sequence do not necessarily change the amino acid sequence of the encoded protein due to degeneracy of the genetic code: in fact, synonymous SNPs do not affect the protein sequence. SNPs not occurring in protein-coding regions may still affect gene splicing, transcription factor binding, messenger RNA degradation, or the sequence of noncoding RNA. SNPs may determine an individual's response to certain drugs, and the susceptibility to environmental factors such as toxins, and risk of developing particular diseases. So far several SNPs have been associated with complex diseases such as heart disease, diabetes, and cancer.

Several SNPs have been identified to modulate zinc intake/ status [43]. Costarelli e colleagues [44] have reported that gene expression of MTs, zinctransporters and inflammatory cytokines are regulated by zinc intake. In addition to zincregulated transcription, genetic polymorphisms of MTs and zinc transporters have been associated with age-related diseases, such as chronic inflammation [45], type 2 diabetes ([46] and cardiovascular diseases (CVD) [47].

In this review, we will focus on the relationship between specific polymorphisms of genes encoding for MTs and zinc transporters and their relationship with zinc status, immune function and some noncommunicable diseases.

\section{GENETIC POLYMORPHISMS OF METALLOTHIONEINS AND ZINC TRANSPORTERS}

As mentioned above, the physiological requirement of trace metal elements is regulated by proteins specialized in the transport and deposit of metals in non-toxic forms. MTs have been very well characterized for their high content in cysteine, an amino acid that plays a key role in the formation of complexes with transition metals resulting in a high capacity to bind heavy metals [48]. At the same time, zinc transporters (ZnTs) family of membrane transport proteins of the solute carrier family control the membrane transport of zinc and regulate its intracellular and cytoplasmic concentrations [49,50]. ZnTs belong to two major groups: i) zinc transporters ( $\mathrm{ZnT}$ ) involved in the controls the efflux of zinc from the cytoplasm out of the cell and from the cytoplasm into vesicles; and ii) zinc importers, Zrt- and Irt-like protein (ZIP), controlling the influx of zinc into the cytoplasm from outside the cell and from vesicles $[48,50]$.

SNPs in genes encoding for MTs and ZnTs can modify different aspects of gene product including its transcription, and also the specific molecular characteristics of the protein resulting e.g. in changes of their $\mathrm{Zn}$ binding affinity [51,52].

Such finding, already 20 years ago, encouraged for the search of genetic variants affecting the functioning of MTs and ZnTs, both necessary for cellular zinc homeostasis.

\subsection{Metallothioneins}

MTs can be considered "cellular buffer" of metals regulating their cellular amounts and being in turn regulated by metals, protecting organisms from harmful effects of highly toxic heavy metals, such as cadmium and mercury, but also regulating the cellular amounts of trace metal micronutrients including zinc, copper, iron, manganese. MT are low molecular weight $(6-8 \mathrm{kDa})$ proteins with high content of cysteine, a low or null content of aromatic amino acids, and spectroscopic characteristics typical of metal-thiolate clusters. Cysteine content and its particular sequence arrangement is crucial for the MTs' ability to form 
complexes with heavy metal ions, those threedimensional structure is influenced in turn by presence of the metal [53]. MTs are particularly abundant in liver and kidney tissues and they are also present in the central nervous system and in mammary, olfactory and thyroid glands, in gastric and intestinal tissues, in hair follicles and in circulating monocytes.

As mentioned above, the main role of MTs is linked to their ability to bind and regulate the homeostasis of essential trace elements, in order to prevent their harmful effects [54]. MTs are polymorphic genes, clustering together on a single chromosomal locus (16q12-22 for homo sapiens [55]), and coded proteins have very similar amino acid sequences. Accordingly, experiments on transgenic mice [56] suggested already 20 years ago that single MT isoforms are not essential for life but rather that MT functions are redundant and compensated by homeostatic mechanisms.

Several studies have demonstrated that MT isoforms are differentially transcribed, translated and maintained in the cell, with a different response to metals. MT1 and MT2 isoforms, which are present in all mammalian tissues, are inducible, with MT2 appearing to be expressed more than
MT1 [57], constituting the $50 \%$ of the total expressions of all metallothionein isoforms [58] and being frequently overexpressed in invasive human breast cancers [59].

\subsubsection{MT polymorphisms}

\subsubsection{MT1A polymorphisms}

According to the database of The National Center for Biotechnology Information (NCBI, http://www.ncbi.nlm.nih.gov/SNP/, May 2018), 98 validated SNPs are present in the human MT1A gene region. Ten are located in the 5'UTR, 14 in the coding sequence, 64 in introns and 10 in the 3'UTR (May 2018). Of these, seven SNPs are mentioned in the literature (rs11076161, rs8052394, rs7196890, rs11640851, rs7190725, rs11076160, rs8049883 and rs11647171) and three have an impact on metabolic disease $[60,61]$ (table 1). rs11076161 and rs8052394 were considered in a search for an association between MT and type 2 diabetes mellitus (T2DM) in a population of 851 Chinese people of Han descent (397 diabetes and 454 controls) [60]. An association of the SNPs was found with the disease and its clinical symptoms, i.e. neuropathy (rs11076161) and serum superoxide dismutase activity (rs8052394) [60].

Table 1. MT polymorphisms, SNP variant and association with metabolic disease

$\begin{array}{lll}\text { MT polymorphisms } & \text { SNP variant } & \text { Associated with }\end{array}$

\begin{tabular}{llll}
\hline MT1A & & & \\
\hline rs11076161 & intron & Diabetic neuropathy & {$[60]$} \\
\hline rs8052394 & missense & T2DM, Serum superoxide dismutase & {$[60]$} \\
\hline rs11640851 & missense & Longevity, Cardiovascular disease, & {$[61]$}
\end{tabular}

MT1B

\begin{tabular}{|c|c|c|c|}
\hline rs964372 & intron & Hyperlipidemia, Diabetic neuropathy & [60] \\
\hline rs7198427 & 5'UTR & Advanced glycation end-products & [62] \\
\hline $\begin{array}{l}\text { rs7197489 } \\
\text { MT2A }\end{array}$ & 5'UTR & Advanced glycation end-products & [62] \\
\hline rs28366003 & 5’UTR & $\begin{array}{l}\text { CKD and DM } \\
\text { B-MT and }-Z n \text { levels in T2DM }\end{array}$ & $\begin{array}{l}{[66]} \\
{[46]}\end{array}$ \\
\hline rs1610216 & 5'UTR & $\begin{array}{l}\text { B-Zn levels, T1DM and cardiovascular } \\
\text { complications } \\
\text { Diabetes }\end{array}$ & [45] \\
\hline rs10636 & 3'UTR & $\begin{array}{l}\text { Atherosclerosis, } \mathrm{B}-\mathrm{Zn}, \mathrm{B}-\mathrm{Cu} \text { and inflammatory } \\
\text { cytokines levels } \\
\text { Diabetic neuropathy and hyperlipidemia in T2DM }\end{array}$ & $\begin{array}{l}\text { [69] } \\
{[66]}\end{array}$ \\
\hline MT4 & & & \\
\hline rs396230 & intron & Blood pressure, serum uric acid & [73] \\
\hline
\end{tabular}

T2DM: Type 2 diabetes mellitus; CKD: chronic kidney disease; DM: diabetes mellitus; MT: Metallothionein; IL-6: Interleukin 6; T1DM: Type 1 diabetes mellitus.

\subsubsection{MT1B polymorphisms:}

103 SNPs are present in the human MT1B gene region. Seven are located in the 5'UTR, 25 in the coding sequence, 54 in introns and 17 in the 3'UTR. Of these, nine SNPs are mentioned in the literature (rs964372, rs8052334, rs7191779, rs2070839, rs1875232, rs7197489, rs7198427, 
rs12051311 and rs61744104) with the first four having a significant association with diseases. As for variants of MT1A, significant association of rs964372 exists with diabetic neuropathy (linked to hyperlipidemia) [60] (as for MT2A, see below). More recently, rs7198427 and rs7197489, initially attributed to the MT1A gene portion, were identified by genome-wide association study (GWAS) as associated to advanced glycation endproducts (AGEs) in diabetic subjects [62].

\subsubsection{MT1E polymorphisms}

The MT1E gene regions contains 188 validated SNPs, ten are located in the 5'UTR, 63 in the coding sequence, 87 in introns and 28 in the 3'UTR. Of these, only four SNPs are mentioned in the literature (rs7403881, rs34166523, rs2070836 and rs708274) and an association of rs7403881 was reported with sporadic amyotrophic lateral sclerosis (SALS) [63]. None of these have been considered to be associated to metabolic disorders.

\subsubsection{MT1F polymorphisms}

112 SNPs have been identified so far in the human MT1F gene region. Eight are located in the 5'UTR, 27 in the coding sequence, 51 in introns and 26 in the 3'UTR. Of these, only one SNP is mentioned in the literature (rs2291956) and still lacks any association with metabolic diseases.

\subsubsection{MT1G and MT1H polymorphisms}

A total of 258 validated SNPs have been found in human MT1G and MT1H gene regions, including 55 variants spread along all regions, but not in the 3'UTRs of the two genes, that bear 17 and 11 SNPs respectively. Twenty 5'UTR SNPs are entirely shared between the two genes. SNPs in intron regions are discretely 94 and 78, plus 25 shared. Finally, coding regions contain respectively 27 and 26 SNPs, plus 10 shared variants. Of these, only five SNPs are mentioned in the literature for both genes, including two in shared gene regions (rs12448654 and rs4784708), and rs2298847, rs2298846 and rs12315 for MT1G and rs9934181, rs2062546 and rs2062545 for MT1H. None of these has been reported so far to have any association with metabolic diseases.

\subsubsection{MT1M polymorphisms}

MT1M variants, whose genomic region partially overlaps with that of the MT1JP pseudogene, include a total of 116 SNPs, 11 in the 5'UTR, 34 in the coding sequence, 59 in introns, and 12 in the 3 'UTR region. Five are mentioned in the literature, three with no associations with diseases (rs2270837, rs1827210 and rs1827208), and two linked with mercury levels in the urine (rs2270836) and in hair (rs9936741) [64].
Activation of MT1M in Hep-G2 cells, upon heavy metals or glucocorticoids exposition, was shown to affect NF-kB activity, therefore potentially involving also metabolic dysfunctions [65].

\subsubsection{MT1X polymorphisms}

139 SNPs have been already reported in the human MT1X gene region. Eleven are located in the 5'UTR, 21 in the coding sequence, 93 in introns and 14 in the 3'UTR. Of these, two SNPs are mentioned in the literature (rs2301234 and rs8051405) but none of them has been associated to metabolic diseases.

\subsubsection{MT2A polymorphisms}

According to the NCBI dbSNP database, the human MT2A gene region contains 68 validated SNPs. Eight are located in the 5'UTR, 14 in the coding sequence, 34 in introns and 8 in the 3'UTR. Among those, three SNPs are cited in the literature having association with diseases: rs28366003, rs1610216 and rs10636.

Recently, the rs28366003 SNP has been associated with increased risk of chronic kidney disease (CKD), and diabetes mellitus (DM) in a large Japanese population [66],

According to the previously reported association of MTs to diabetes and metabolic diseases [67], an association with the disease in elderly patients was reported with two more SNPs within MT2A. The first one, rs1610216, was linked to higher risk for type 1 diabetes mellitus (T1DM) and cardiovascular complications (chronic inflammation, higher plasma levels of IL-6 and glycosylated hemoglobin), together with lower plasma zinc levels, in Italian atherosclerotic patients [45]. rs1610216 has been confirmed to be associated to diabetes also in Bulgarian diabetic patients [68]. The second one, rs10636, was linked to higher risk of atherosclerosis and carotid plaques, increased inflammatory cytokines and decreased zinc and copper plasma levels [69]. rs10636 role in diabetes has been confirmed by Yang and coworkers that observed variants of the SNP in T2DM patients with diabetic neuropathy and hyperlipidemia [60].

\subsubsection{MT3 polymorphisms}

The expression of MT3 (also known as growth inhibitory factor), is primary in the central nervous system [70]. According to the NCBI dbSNP database, the human MT3 gene contains 131 validated SNPs. 26 are located in the 5'UTR, 22 in the coding sequence, 72 in introns and 11 in the 3'UTR. Among those, three SNPs are cited in the literature and two (rs45570941 and rs11644094) 
have been reported to be associated with distinct pathologies, but not to metabolic dysfunction.

\subsubsection{MT4 polymorphisms}

MT4 was isolated from digestive and neonatal skin epithelia [71] and showed better $\mathrm{Cu}$ binding properties than MT1 [72]. Two MT4 SNPs are present in the coding sequence and 55 in introns. Only one association has been reported, i.e. that of rs396230, with blood pressure and serum uric acid values in car battery workers [73].

\subsection{ZnT zinc transporters}

$\mathrm{ZnT}$ are membrane proteins that regulate its intracellular and cytoplasmic concentrations of zinc through its transport. They differ from the zinc importers, Zrt- and Irt-like proteins (ZIP), because they control the efflux of zinc from the cytoplasm out of the cell (Znt1) and into vesicles (all other except ZnT9, considered a misnomer) [74], while the latter, not considered in this review, control the influx of zinc into the cytoplasm from outside the cell and from vesicles. This review will not specifically address on ZIP and will be mainly focus on $\mathrm{ZnT}$.

The SLC30 family of ZnT zinc transporters family comprises 10 mammalian members that belong to the large superfamily of CDF transporters that also includes zinc transporters in bacteria, fungi, nematodes, insects and plants [75]. Based on structural information obtained in the bacterial homolog YiiP [76], CDF family members are predicted to have six trans-membrane domains (TM) and a histidine/serine-rich loop between TM4 and TM5, except for ZnT5 which contains additional TM domains at the $\mathrm{N}$-terminal. At the $\mathrm{C}$ terminal, ZnTsbear long tails, from 82 amino acids for ZnT7 to 203 for ZnT6. Differently from MTs, high length heterogeneity exists for the amino acid sequences upstream of the first TM domain where different subcellular targeting signals are present. Based on sequence similarities, ZnT family members are grouped into four subfamilies with SLC30A5 (ZnT5) and SLC30A7 (ZnT7) in subfamily I, SLC30A2/3/4 and SLC30A8 (ZnT2, ZnT3, ZnT4 and ZnT8) in subfamily II, SLC30A1 (ZnT1) and SLC30A10 (ZnT10) in subfamily III, and SLC30A6 (ZnT6) and SLC30A9 (ZnT9) in subfamily IV.

Expression of $\mathrm{ZnT}$ is in general ubiquitous (ZnT1) but ZnT5, ZnT6, ZnT7, and ZnT9 are highly expressed in certain districts and tissuespecific with respect to other tissues and characterized by specific temporal patterns. For example, the members of the subfamily II are restricted to secretory tissues such as lactating mammary glands, glutamatergic neurons, prostate, and pancreatic $\beta$-cells. A high expression of ZnT5, ZnT6 and ZnT7 has been reported in the heart [77], in the brain [78] in the intestine [79], respectively while ZnT10 expression is limited to brain and liver [80].

ZnT1 expression in the placenta and other tissues is induced by dietary zinc intake [81] and is switched on during post-implantation period in trophoblasts and in the maternal deciduum [82]. The activation depends on MTF1 binding to MRE of $\mathrm{ZnT} 1$ promoter [83]. On the other hand, dietary zinc intake reduces ZnT5 expression both in vitro in Caco 2 cells and in vivo in the ileal mucosa [84].

Differently from MT KO, ZnT silencing has serious consequences and $\mathrm{ZnT} \mathrm{KO}$ is hardly compatible with life, indicating a crucial role of these transporters. For instance, ZnT1 KO mice are embryonically unviable because of impaired zinc transfer from the mother [85]. ZnT5 [86] and ZnT7 [79] are localized on the membrane of the Golgi apparatus and in cytoplasmic vesicles. ZnT7 KO mice display poor growth, with decreased adiposity and insulin resistance [87]. Znt8 $\mathrm{KO}$ mice have an impaired insulin secretion and zinc-insulin crystals $[88,89]$.

\subsubsection{ZnT polymorphisms}

\subsubsection{ZnT1, ZnT4, ZnT5, ZnT6, ZnT7 and ZnT9 polymorphisms}

According to the NCBI database (May 2018), 152 and 1482 validated SNPs are present in the human $\mathrm{ZnT} 1$ and ZnT4 gene regions, respectively. With respect to $\mathrm{ZnT} 1$, four are located in the 5'UTR, 93 in the coding sequence, 49 in introns and 4 in the 3'UTR. Regarding ZnT4, 109 are located in the 5'UTR, 90 in the coding sequence, 1256 in introns and 27 in the 3 'UTR.

1527 SNPs are present in the ZnT5 gene region, 14 in the 5'UTR, 172 in the coding, 1265 in introns and 76 in the 3'UTR. Among those, only two SNPs have publications in PubMed, rs337253 and rs164578, with no association with diseases. However, rs337253 has been proposed to be associated with the expression of antioxidant response element (ARE)-regulated genes, and in particular to NRF2-mediated antioxidant response pathway [90], which is involved in metabolic diseases [91].

Near three thousand SNPs have been identified in the ZnT6 gene region, 99 in the 5'UTR, 173 in the coding, 2309 in introns and 217 in the 3'UTR. Finally, almost four thousand SNPs are present in both Znt7 and Znt9 gene regions. Znt7 has 45 in the 5'UTR, 133 in the coding, 3292 in introns and 
267 in the 3'UTR. Similarly, the majority of ZNT9 SNPs are in the intron region (3496), 11 are located in the 5'UTR, 129 in the coding sequence and 43 in the 3'UTR. Several links are present for these three SNPs in PubMed citations, but no associations with metabolic diseases have been reported, so far.

\subsubsection{ZnT2 polymorphisms}

The human ZnT2 gene region presents 422 SNPs. Eighteen are located in the 5'UTR, 107 in the coding sequence, 256 in introns and 41 in the 3'UTR (May 2018). Several are mentioned in the literature and the number is actually underestimated because of the presence of rs-unclassified variants (table 2). So far, no association with metabolic disease has been reported.

Table 2. ZnT polymorphisms, SNP variant and association with metabolic disease

\begin{tabular}{|c|c|c|c|}
\hline ZnT polymorphisms & SNP variant & Associated with & Ref. \\
\hline \multicolumn{4}{|l|}{ ZnT2 } \\
\hline rs35623192 & missense $\mathrm{R}^{340} \mathrm{C}$ & T2DM & $(100)$ \\
\hline rs35235055 & missense $\mathrm{L}^{23} \mathrm{P}$ & T2DM & $(100)$ \\
\hline \multicolumn{4}{|l|}{ Znt8 } \\
\hline \multirow[t]{8}{*}{ rs13266634 } & missense $\mathrm{R}^{325} \mathrm{~W}$ & T2DM & {$[94-96,103-110]$} \\
\hline & & T2DM drug therapeutic efficacy & [105] \\
\hline & & Proinsulin conversion & {$[120-121]$} \\
\hline & & Insulin secretion & {$[122-123]$} \\
\hline & & T1DM & {$[125-127]$} \\
\hline & & Dyslipidemia & [129] \\
\hline & & Chronic coronary artery disease & [128] \\
\hline & & Muscle strength and size & [130] \\
\hline rs16889462 & missense $\mathrm{R}^{325} \mathrm{Q}$ & T2DM and drug therapeutic efficacy & {$[105]$} \\
\hline rs11558471 & 3'UTR & T2DM & {$[131-135]$} \\
\hline rs3802177 & 3'UTR & T2DM & {$[98,132,136]$} \\
\hline \multirow[t]{3}{*}{ rs2466293 } & 3'UTR & T2DM & [137] \\
\hline & & T1DM & {$[138]$} \\
\hline & & Gestational diabetes mellitus & [139] \\
\hline
\end{tabular}

T2DM: Type 2 diabetes mellitus; T1DM: Type 1 diabetes mellitus

\subsubsection{ZnT3 polymorphisms}

According to the NCBI database, 1103 validated SNPs are present in the human $\mathrm{ZnT3}$ gene region. 127 are located in the 5'UTR, 178 in the coding, 759 in introns and 39 in the 3'UTR. Several ZnT3 SNPs have PubMed links in neurological disorders and with $\mathrm{Zn}$ status, which is consistent with the phenotype of the mouse $\mathrm{KO}$ [92], but none was associated to metabolic disease or diabetes.

\subsubsection{ZnT8 polymorphisms}

According to the NCBI database more than eight thousand validated SNPs are present in the human ZnT8 gene regions, the majority are in the intron region (8021), 56 are located in the 5'UTR, 141 in the coding sequence and 134 in the 3'UTR. 32 SNPs have links with PubMed citations, and six have an association with diseases.

rs13266634 has a number of citations (more than two hundred) related to the $\mathrm{R}^{325} \mathrm{~W}$ variant, a well-known susceptibility locus of T2DM, since its finding ten years ago in several genome-wide association studies conducted in European [93-96], Asian [97-107], Russian [108], Tunisian [109], Mexican Mestizo [110] (but not Mexican [111,112], African [113], Hispanic American [114], Qatari [115] nor south Iranian [116]) subjects (reviewed in $[117,118]$. These findings are consistent with ZnT8's major role as transporter of zinc, necessary for insulin maturation, into secretory pancreatic $\beta$-cells [119]. In fact, impaired proinsulin conversion $[120,121]$ and insulin secretion $[122,123]$ have been found in carriers of the $\mathrm{R}^{325} \mathrm{~W}$ variant. Recent reports demonstrate that T2DM risk depends on different zinc transport kinetics of the variants [124]. Because of its role in $\beta$-cell functions, rs13266634 SNP was tested and found implicated also in T1DM [125-127], and in cardiovascular diseases incidence [128]. Other studies of associations of rs13266634 variants include implication with dyslipidemia in 
HIV/hepatitis C virus co-infected patients [129] and with skeletal muscle strength and size [130].

Other ZnT8 SNPs implicated in T2DM were reported (frequently in high linkage disequilibrium with rs13266634), i.e rs16889462 [105], rs11558471 [131-135] and rs3802177 [98,132,136] and rs2466293 [137]. rs16889462, actually concerning the same codon $325\left(\mathrm{R}^{325} \mathrm{Q}\right)$ involved in rs13266634, found in a single African-Americans family, but not in Caucasians, was associated like rs13266634 with repaglinide therapeutic efficacy in Chinese patients [105]. rs2466293 has been recently associated with T1DM in Latin Americans [138] and was identified by means of in silico as a miR-binding SNP in Chinese pregnant women affected by gestational diabetes mellitus (GDM) [139]. On the other hand, rs13266634 lowered GDM risk in in European women [140] and was excluded as a risk factor for Euro-Brazilian ones [141].

\subsubsection{ZnT10 polymorphisms}

According to the NCBI database, the human ZnT10 gene region contains 1799 validated SNPs. 50 are located in the 5'UTR, 125 in the coding sequence, 1571 in introns and 53 in the 3'UTR. Among those, six intron SNPs are cited in the literature to be associated with metal physiology but no reports about any association with metabolic syndrome has been reported.

\section{GENETIC POLYMORPHISMS, ZINC STATUS AND ALTERATIONS IN IMMUNE AND INFLAMMATORY FUNCTION}

Zinc has been demonstrated to have both antioxidant and anti-inflammatory roles. It has been described as a "second messenger" for immune cells, with a range of transcription factors associated with the gene expression of inflammatory cytokines and with adhesion molecules having been reported to be zinc dependent [3]. Zinc has been demonstrated to have a role in both innate and adaptive immune function [23] with a long established relationship recognised between zinc deficiency and immune dysfunction [142]. Via its availability, which is closely regulated by a number of transporters and regulators, zinc functions as a modulator of immune response. Perturbations of these processes may alter zinc availability, impacting on the survival, proliferation and maturation of cells associated with both innate and adaptive immunity [143].
Patients who are clinically zinc deficient may present range of immune-related symptoms including lymphopenia, decreased ratio of T-helper (Th) cells to cytotoxic T-cells; a decrease in the cellular natural killer cell activity and an increase in cytoxicity. Such deficiency is associated with chronic diarrhoea, administration of parenteral nutrition lacking in zinc or as a result of excessive consumption of alcohol, as well as being found in patients with the malabsorption disorder, Acrodermatitis Enteropathica (AE). Owing to the prevalence of marginal zinc deficiency in older people there is likely to be a correlation between zinc status and impaired immune function in elderly people. Increased risk of inflammatory conditions, increased susceptibility to infection, autoimmune diseases, cardiovascular disease and cancer are all associated with immunosenescence the age-related alterations in immune function [6, 24, 36].

Changes in immune function associated with zinc deficiency and ageing show many similar features in both innate and adaptive immunity and neutrophil function which led [24] to propose the existence of a tight relationship between zinc deficiency and immunosenescence. Zinc supplementation may, therefore, be particularly relevant in older people in the prevention, reduction or delay of disease. However, the data from intervention studies to date are conflicting. This may be owing to the usage of different doses, durations and forms of zinc supplements utilised. In addition in the presence of high oxidative stress high doses of zinc may trigger apoptosis of immune cells [144] The accumulation of zinc may reach toxic levels resulting in the aberrant activation of zinc-dependent enzymes such as PARP-1 with a role in genomic stability or promote the uptake of excessive levels of calcium into the cells, resulting in cell death [24]

It has been stated that the key factors underpinning intracellular zinc levels during ageing are increased expression of MTs and defective zinc transporters, leading to increased sequestration of zinc and low intracellular free zinc content [145]. In its role as a "second messenger" within the immune system, zinc may alter the signalling cascades that promote antioxidant and immune defence [146]. In the elderly low free zinc ion availability and increased MTs levels may result in compromised antioxidant and immune response, increasing inflammation accompanied by repeated infections and risk of degenerative disease [145]. Although data from intervention studies are contradictory, there is evidence that zinc supplementation may have a positive impact on DNA repair and increase the expression of some 
zinc transporters genes, improving zinc homeostasis and reducing infections [145,147,148]. Following a systematic review of the literature examining the relationship between zinc status and autoimmunity Sanna and coworkers [149] have identified a relationship between zinc homeostasis imbalance and the state of autoimmunity, suggesting a need to commence a screening campaign for the evaluation of zinc levels in children. They have also proposed a clinical trial in populations at higher risk of autoimmunity to investigate the possibility of personalised zinc supplementation for the prevention or treatment of autoimmune diseases.

Giacconi et al. [47] reviewed the proinflammatory genetic factors and zinc status in older atherosclerotic subjects and stated that the identification of polymorphisms of pro-and antiinflammatory cytokines and their interaction with nutrients, such as zinc that impact on Th1/Th2 balance, represents an opportunity for predicting atherosclerotic plaque formation and targets for future therapies. Nonetheless, conflicting data exist between polymorphisms, the occurrence of atherosclerosis and the influence on zinc homeostasis.

Genetic make-up may influence the response to zinc supplementation, with recent studies indicating that polymorphisms in IL-6-174 G/C and MT1a $+647 \mathrm{~A} / \mathrm{C}$ loci may affect the impact of zinc supplementation on antioxidant and immune function in older people [24, 150,151]. In the rare, inborn disorder of zinc metabolism, AE, a mutation in ZIP 4 (SLC 49A4) importer gene results in severe zinc deficiency symptoms [152]. A variety of other polymorphisms in zinc-related proteins have been implicated in a range of disorders and it has been suggested that zinc, via zinc transporters, may affect DNA stability resulting in altered zinc homeostasis and metabolism [43]. Through zinc fingers, extraction part of several transcription factors, zinc is involved in the DNA replication processes which are necessary for a wide range of key cellular processes [145]. Some of these are transcription factors which are involved in the regulation of pro-inflammatory cytokines (IL6 and $\mathrm{TNF}_{\alpha}$ ) and heat shock proteins (Hsp70) [153]

Giacconi et al. [154] investigated the association of Hsp70 $1267 \mathrm{~A} / \mathrm{G}$ and $\mathrm{TNF}_{\alpha}-308$ G/A polymorphisms with pro-inflammatory mediators and zinc status in elderly people. Utilizing a linear regression modelling approach to examine additive, dominant or recessive associations of each SNP with pro-inflammatory mediators, MT and zinc status measures they concluded that $\mathrm{HsP} 70 \mathrm{~A} / \mathrm{G}$ is linked to the production of pro-inflammatory cytokines in healthy elderly people, which might be involved in determining how vulnerable individuals are to inflammatory disease. They also concluded that $\mathrm{TNF}_{\alpha}-308 \mathrm{G} / \mathrm{A}$ SNP do not impact on production of pro-inflammatory cytokines but that both SNP are associated with levels of creatinine. Giacconi and colleagues [52] also investigated the role of ZIP 2 Gln/Arg/Leu (rs2234632) polymorphism on zinc homeostasis and inflammatory response following zinc supplementation, again in elderly volunteers. Enhanced IL-6, $\mathrm{TNF}_{\alpha}$ and RANTES plasma level were demonstrated in ZIP2 $\mathrm{Leu}^{-}$ (Arg43Arg) carriers. This was associated with decreased free cytosolic zinc and an up-regulation of the ZIP2, ZIP8 and Znt1 transporters. Upon zinc supplementation, the volunteers who were Leushowed a decrease in inflammatory mediators.

Wong et al.[155] investigated the impact of zinc deficiency on cellular immune activation and the epigenetic mechanisms which might enhance inflammation. They concluded that the zinc deficiency induced inflammatory responses at least partly by promoting irregular immune cell activation and altering promoter methylation.

Borghaei et al. [156] demonstrated that the zinc-binding protein -89 (ZIP-89) cooperates with NF-kB to regulate matrix metalloproteins (MMPs) expression as a response to inflammatory cytokine. MMPs have important roles in physiological tissue remodelling and wound healing as well as roles in the pathology of a range of disease conditions and transcriptional mechanisms are key in regulating healthy physiological level. ZBP-89 has been reported to bind the MMP-3 promoter at a site which is polymorphic, namely $5 \mathrm{~A} / 6 \mathrm{~A}$ along with NF-kB. Tissue MMP-3 protein levels are affected by this polymorphism. They reported that ZBP-89 was necessary for maximal induction of both genes by IL-B and $\mathrm{TNF}_{\alpha}$ and suggested a role for ZBP-89 in expression of MMP-1 and in inflammatory processes via interaction with NF-kB $[156,157]$. In 2010 Mocchegiani et al. [158] reported that the contradictory data from studies investigating the association between IL-6 polymorphisms, longevity and age-related diseases appear to be as a result of the interaction of these inflammatory processes with dietary intake, providing further evidence for a link among gene interaction and frailty in older age. Mocchegiani et al. [145] provide further supporting evidence of micronutrient-gene interactions related to inflammatory/immune response and antioxidant activity in ageing and propose that elucidating these associations could give a formula of personalised zinc supplementation or chelation to promote healthy ageing and long life. 


\section{GENETIC POLYMORPHISMS INVOLVED IN ZINC STATUS AND NON COMMUNICABLE DISEASE}

Noncommunicable diseases (NCDs), also known as chronic diseases are the result of a combination of genetic, physiological, environmental and behaviours factors. The main types of NCDs are cardiovascular diseases, metabolic disorders, cancers and chronic respiratory diseases [159]. The metabolic disorder frequently known as the "metabolic syndrome" (MetS), is defined by a clustering of abdominal obesity, high level in serum concentration of triglycerides, a lower quantity level of high-density lipoprotein (HDL) cholesterol, high blood pressure and an increased fasting blood glucose level $[160,161]$.

In Europe the MetS prevalence is approximately $25 \%$ of adults, with a progressive increase in the elderly population [162]. Moreover, the heritability for MetS ranges from 10\% to $30 \%$ [163,164]. Meta-analyses revealed a combined heritability estimate for Adult Treatment Panel-III MetS of 0.24 (95\% CI, 0.11-0.36) and for the MetS severity score of 0.50 (95\% CI, -0.05 to 0.99) [165], indicating that this syndrome is in part inheritable. Knowledge of the exact genetic factors underlying MetS development may help to explain why the features of MetS frequently co-occur within one individual [166].

Several studies have demonstrated a relationship between obesity and $\mathrm{Zn}$ homeostasis. In particular, a significant decrease of blood $\mathrm{Zn}$ levels and an increase of urinary concentrations have been found in obese patients [167-169]. Moreover, erythrocyte $\mathrm{Zn}$ levels have been found to be associated with BMI and waist circumference [170]. In obesity, low nutritional $\mathrm{Zn}$ status is also associated with the aggravation of obesity-related metabolic disturbances such as insulin resistance, inflammation, and altered lipid profile [44, 171] and numerous studies dealing with zinc supplementation reported an improvement of blood pressure, glucose, and LDL cholesterol serum level [172]. Zinc plays a role in insulin signal transduction through the modulation of insulin receptor phosphorylation and of the activities of phosphoinositide-3-kinase, phosphoinositide-dependent kinase 1, Akt/protein kinase $\mathrm{B}$ and glycogen synthase kinase 3 , which are part of the insulin signaling pathway [173]. The interaction between zinc status, obesity, altered glucose metabolism and other metabolic disorders may be at least partially mediated by the pathological-induced modulation of zinc transporters that regulate cellular and intracellular Zn fluxes [174].

In recent years, polymorphisms in the solute carrier family 30 member 8 (SLC30A8) gene (ZnT8) with increased type 1 [175-180] and type 2 diabetes [177, 181-184] susceptibility were found (see also paragraph 2). In fact, a connection between the functionality of SLC30A8 has been observed and zinc concentration in plasma was shown able to influence glucose tolerance [185].

Type 1 diabetes is characterized by a destruction of pancreatic $\beta$-cells, resulting in absolute insulin deficiency causing hyperglycemia through the involvement of autoimmunemechanisms and genetic and environmental factors, that can accelerate or slow down the clinical course of the disease [179]. The mechanisms involved in the autoimmune reaction against specific antigens of the pancreatic islands may involve ZnT8 which has been identified as a new target of cell mediated and humoral autoimmunity in T1DM [186]. The C allele of the rs13266634 SNP was found associated with younger age onset of T1DM patients [176] but not in a Swedish population [187]. Furthermore, Swedish subjects had a lower frequency of the R325 (C/C) genotype than the non-Swedes, which could reduce genetic predisposition to T1DM [186]. While rs11203203 was identified as a genetic marker in children, AA genotype conferred a higher risk of persistent islet autoimmunity and type 1 diabetes [188]. Both SLC30A8 polymorphisms were found to be associated with the HLA-DQ gene. However, further research will serve to better understand the role of SLC30A in the pathogenesis of type 1 diabetes across different population and its association with other genes and HLA which may permit major advances in future diagnostic and therapeutic approaches.

Type 2 diabetes is a progressive and chronic metabolic disease and it is characterized by peripheral insulin resistance and pancreatic beta $\beta$ cell dysfunction with a growing interest in the role of zinc signaling in this disease $[173,189]$. GWAS of the past decade have identified variants in the human SLC30A8 gene as affecting the risk of Type 2 Diabetes [189]. Genome-wide association studies demonstrate an association of the above mentioned rs13266634 SNP of ZnT8 with decreased insulin release and T2DM susceptibility [43]. In particular, the common allele $\mathrm{C}$ of rs13266634 was associated with increased odds of T2DM in Europeans and Asians populations [186]. However, when $\mathrm{Zn}$ intake was taken into consideration, the $\mathrm{C}$ allele of rs13266634 was associated with lower odds of T2DM after zinc supplementation [182]. On the 
other hand, Maruthur et al [190] reported that carriers of the $\mathrm{T}$ allele have increased insulin response after supplementation with $\mathrm{Zn}$ and thus may benefit more from $\mathrm{Zn}$ supplementation. A recent study identified 44 novel SLC30A8 variants; the minor alleles of rs2464591, rs2466296, rs2466297, and rs2466299 were associated with improvement in $\beta$-cell function, while carriers of the minor allele of rs2466293 had worsened functions. However, no association was observed between $\mathrm{Zn}$ intake and SNPs on diabetes incidence suggesting a limited role for dietary manipulation in affecting risk in relation to the SNPs identified [191].

As systematically reported in paragraph 2 , there is another common SNP rs11558471 A/G in 3'-UTR of the SLC30A8 gene. A cross-sectional metaanalysis on 14 cohorts assessed the interaction of 20 genetic variants known to be related to glucose metabolism traits among individuals of European ancestry [192]. The strongest interaction effect was detected for rs11558471, where carriers of the A allele had increased fasting glucose. Moreover, a strong linkage disequilibrium between rs11558471 and rs13266634 was observed in this study. The results show that an increase in $\mathrm{Zn}$ intake decreases diabetes risk in A allele carriers, suggesting that $\mathrm{Zn}$ intake has an inverse association with fasting glucose plasma concentration.

All these observations highlight the need to generate personalized recommendations of $\mathrm{Zn}$ according to the genotype of SLC30A8 [43]. Similar results were also found in the Asian population [193-195]. In this population, another SNP (rs3802177) has been identified in the SLC30A8 gene which increases the risk of type 2 diabetes [196]. Rs3802177 showed the strongest association with T2D compared to the other SNP in the SLC30A8 gene [194]. Moreover, this SNP is strongly linked $\left(r^{2}=0.83\right)$ to another SNP in the SLC30A8 gene, rs13266634 [196]. However only about $10 \%$ of the total hereditary risk of T2D can be attributed to SLC30A8 genes and this lack could be due to rare variants and epigenetic factors [197]. Flannick et al. [198] genotyped 150,000 individuals across five ethnicities and identified 12 rare protein-truncating variants in SLC30A8 that overall have reduced risk of T2DM for over $60 \%$. Of the 12 variants, two common protein-truncating variants (p.Arg138X and p.Lys34SerfsX50) were associated with T2DM protection. The association of common alleles of SLC30A8 polymorphisms with T2DM implicates that this is a susceptibility gene in T2DM, while loss of SLC30A8 function may have a protective effect in the diseases. With regard to epigenetics, a significant increase in DNA methylation levels in the SLC30A8 gene has been recently observed in patients with T2DM [197].

Independently of SNPs located within genes encoding for proteins involved in $\mathrm{Zn}$ metabolism and trafficking, allelic variants located in the gene region encoding for the zinc finger of transcription factors have been reported to play an important role in determining the genetic risk of metabolic disease. Among genetic polymorphisms involved in lipid metabolism and hypertension and associated with zinc, there is rs964184 within the Zinc Finger Protein 259 (ZNF259). Mirhafez and coworkers [199], in a study performed in an Iranian population, found that the risk of MetS is increased in individuals carrying the $\mathrm{G}$ allele with an $\mathrm{OR}$ of $2.52(95 \% \mathrm{CI}=1.33-4.77 ; \mathrm{P}=0.005)$. Likewise, others authors found a positive association between ZNF259 and serum lipid levels in different populations [200,201]. Wu et al. [202], performed a case-control study on 1,812 MetS patients and 2,036 controls from the Northeastern of China and found significant differences $(\mathrm{p}<0.05)$ between the two population groups within the ZNF259 rs964184 and rs2075290 genotypes, that could thus be associated with triglycerides levels, blood pressure, abdominal obesity, fasting hyperglycemia and HDL-C levels. Similar results were found by Ueyama et al. [203] on an Japanese population including 1,822 subjects with MetS and 1,096 controls. A GWAS performed on 815 Hispanic children seeking genetic markers associated with obesity-related traits identified among several genes involved in obesity pathogenesis also variants in the APOA5-ZNF259 region, in particular linked with triglycerides levels $(p=2.5-4.8 E-08)$ [204].

\section{CONCLUSIONS}

A constant daily supply of $\mathrm{Zn}$ is necessary to maintain an optimal nutritional status and health. Both zinc deficiency and excess may lead to important health impairment such as in immune function, cardiovascular diseases, type 2 diabetes. Zinc homeostasis is therefore critical to protect against infection and reduce the risk of inflammatory disease and other chronic pathological conditions. There is a growing body of evidence demonstrating links between the genetic factors and requirements for zinc and the consequential impact on immune function and other aspects of human health, especially and critically in ageing.

Zinc homeostasis is mediated by metallothioneins (MTs) and zinc transporters. Zinc 
status and specific polymorphisms of genes coding for zinc-transporters have been in fact associated with chronic diseases. Base mutation experiments have demonstrated that specific DNA mutations can modify the structure and the expression of MTs and affect their ability to bind metal, through the impairment of transcription factors' activity to MTs' regulatory elements [51]. Indeed, as here summarized, SNPs affect several MTs functions linked to metal binding, from cancer to metabolic syndrome-related pathologies and their complications. Overall, 18 MT SNPs with an impact on pathological processes are known and 16 are in non-coding regions. They are present in every MT gene class, excluding 3 out 8 MT1 genes (E, F, G and H) though 12 SNPs occur in this class. Main implications are on metal disbalance (8 SNPs) and cancer (6 SNPs). Metal-related functions are also impaired by specific SNPs in ZnT genes and a total of 28 SNPs are involved in pathological processes. Their effects include insulin levels [120-123] and severe complications like dyslipidemia and diabetes [94-110,125-127, 131139]. However, differently from MT SNPs, the majority of ZnT variants involves non-synonymous changes in the coding region of genes (16 out of 28). Variants belong mainly to ZnT2 and ZnT8 genes, according to genes' roles in insulin secretion $[88,89]$. Nonetheless, like for MTs, other functions, linked to cardiovascular [128], are impaired.

New studies are needed to allow a more comprehensive understanding of MT and ZnT mechanisms of action and of the effects of their common genetic variants. Moreover, the clear impact of zinc in diseases strengthens the need of more studies in transporters' role in the regulation of physiological processes, for the set-up of accurate biomarkers able to monitor and detect subtle changes in cellular zinc homeostasis. Genetic studies have demonstrated that common DNA polymorphisms in some metallothioneins and zinc transporters confer susceptibility for some chronic diseases but the information is still limited and there is a need to better clarify the interactions between genes and other molecules. Furthermore, when considering the assumption of $\mathrm{Zn}$ the results remain controversial. This highlights the importance in the near future to clarify genenutrient interactions and provide a clear understanding of any intervention requirements.

There is a need to communicate this scientific information to health professionals in a way, which will allow them to translate this into dietary and behavioural recommendations which will promote human health, particularly for the elderly.
LIST OF ABBREVIATIONS (not included in the text)

$$
\begin{array}{ll}
\text { Irs2 } & =\text { insulin receptor substrate } \\
\mathrm{Akt} & =\text { Protein kinase } \mathrm{B}(\mathrm{PKB}) \\
\mathrm{kDa} & =\text { kilodalton } \\
\mathrm{UTR} & =\text { Untranslated region } \\
\mathrm{CDF} & =\text { Cation Diffusion Facilitator } \\
\mathrm{NF}-\kappa \mathrm{B} & =\text { nuclear factor kappa-light-chain- } \\
\text { enhancer of activated } \mathrm{B} \text { cells }
\end{array}
$$

$$
\begin{aligned}
& \text { IL-6 = Interleukin } 6 \\
& \text { NCBI = National Center for Biotechnology } \\
& \text { Information }
\end{aligned}
$$

MRE = Metal response element

$\mathrm{KO}$ mice $=$ knockout

NRF2 = Nuclear factor E2-related factor 2

PARP-1 = Poly (ADP-ribose) polymerase-1

HSP70 = Heat Shock Protein 70 kilodaltons

TNF $\alpha=$ Tumor necrosis factor alpha

RANTES = Regulated on activation, normal T-cell expressed, and secreted

APOA5 = Apolipoprotein A5

\section{CONSENT FOR PUBLICATION}

Not applicable.

\section{CONFLICT OF INTEREST}

The authors declare no conflict of interest, financial or otherwise.

\section{ACKNOWELEDGEMENTS}

Declared none

\section{REFERENCES}

[1] Prasad AS, Miale A, Farid Z, Shulert A, Standstead HH. Zinc metabolism in patients with the syndrome of iron deficiency anaemia, hypogonadism and dwarfism. J Lab Clin Med 1963; 61:53749.

[2] Prasad AS. Impact of the discovery of human zinc deficiency on health. J Trace Elem Med Biol 2014a; 28:357-363.

[3] Prasad AS. Zinc: an antioxidant and antiinflammatory agent: Role of zinc in degenerative disorders of aging. J Trace Elem Med Biol 2014b; 28:364-371. 
[4] Roohani N, Hurrell R, Kelishadi R, Schulin R. Zinc and its importance for human health: An integrative review. J Res Med Sci. 2013;18(2):144-57.

[5] Fukada T, Yamasaki S, Nishida K, Murakami M, Hirano T. Zinc homeostasis and signaling in health and diseases: zinc signaling. J Biol Inorg Chem 2011; 16: 1123-1134.

[6] Wessels I, Maywald M and Rink L. Zinc as a gatekeeper of immune function. Nutrients 2017; 9:1286

[7] Fukada T, Kambe T. Molecular and genetic features of zinc transporters in physiology and pathogenesis. Metallomics 2011; 3: 662-674.

[8] Subramanian VK, Deepe GS. Metallothioneins: Emerging Modulators in Immunity and Infection. Int $\mathbf{J}$ Mol Sci 2017;18(10). pii: E2197.

[9] Cousins RJ, Liuzzi JP and Lichten LA. Mammalian zinc transport, trafficking, and signals. J Biol Chem 2006; 281: 24085-24089

[10] Thornalley PJ, Vašák M. Possible role for metallothionein in protection against radiation-induced oxidative stress. Kinetics and mechanism of its reaction with superoxide and hydroxyl radicals. Biochim Biophys Acta 1985; 827: 36-44.

[11] Freedman JH, Ciriolo MR, Peisach J. The role of glutathione in copper metabolism and toxicity. J Biol Chem 1989; 264: 5598-5605.

[12] Thomas JP, Bachowski GJ, Girotti AW. Inhibition of cell membrane lipid peroxidation by cadmium- and zincmetallothioneins. Biochim Biophys Acta 1986; 884: 448-61.

[13] Sato M, Bremner I. Oxygen free radicals and metallothionein. Free Radic Biol Med. 1993; 14: 325-37.

[14] Penkowa M, Camats J, Giralt M, et al. Metallothionein-I overexpression alters brain inflammation and stimulates brain repair in transgenic mice with astrocyte Targeted interleukin-6 expression. Glia. 2003; 42(3):287-306

[15] Ambrosini G, Adida C, Sirugo G, Altieri DC. Induction of apoptosis and inhibition of cell proliferation by survivin gene targeting. J Biol Chem.1998; 273: 1117782.

[16] Asmussen JW, Von Sperling ML, Penkowa M. Intraneuronal signaling pathways of metallothionein- J Neurosci Res 2009; 87: 2926-36
[17] Jing L, Yang M, Li Y, et al. Metallothionein prevents doxorubicin cardiac toxicity by indirectly regulating the uncoupling proteins 2. Food Chem Toxicol. 2017;110: 204-213.

[18] Huang L, Yan M, Kirschke CP. Overexpression of ZnT7 increases insulin synthesis and secretion in pancreatic betacells by promoting insulin gene transcription. Exp Cell Res 2010; 316: 2630-43.

[19] Huang L, Kirschke CP, Lay YAE, Levy LB, Lamirande DE, Zhang PH. Znt7-null mice are more s usceptible to dietinduced glucose intolerance and insulin resistance. J Biol Chem 2012; 287: 33883-96.

[20] Hardyman JEJ, Tyson J, Jackson KA, et al. Zinc sensing by metal-responsive transcription factor 1 (MTF1) controls metallothionein and ZnT1 expression to buffer the sensitivity of the transcriptome response to zinc. Metallomics. 2016; 8(3):337-43.

[21] Chen Y-H, Kim JH, Stallcup MR. GAC63, a GRIP1-dependent nuclear receptor coactivator. Mol Cell Biol 2005; 25: 5965-72.

[22] Chen YH, Yang CK, Xia M, Ou CY, Stallcup MR. Role of GAC63 in transcriptional activation mediated by beta-catenin. Nucleic Acids Res 2007; 35: 2084-92.

[23] Maares $M$ and Haase H. Zinc and immunity: An essential interrelation. Arch Biochem Biophysics 2016; 611:58-65

[24] Mocchegiani E, Romeo J, Malavolta M, et al. Zinc: dietary intake and impact of supplementation on immune function in the elderly. Age 2013; 35:839-860

[25] Maywald M and Rink L. Zinc homeostasis and immunosenescence. $\mathrm{J}$ Trace Elem Med Biol 2015; 29:24-30

[26] Kambe T, Hashimoto A, Fujimoto S. Current understanding of ZIP and ZnT zinc transporters in human health and diseases. Cell Mol Life Sci 2014; 71: 3281-3295.

[27] Stanstead HH, Prasad AS, Schulbert AR, et al. Human zinc deficiency, endocrine manifestations and response to treatment. Am J Clin Nutr 1967; 20:422-42.

[28] National Academy of Science. Trace elements: zinc. In Recommended dietary allowances. $8^{\text {th }}$ ed. Washington. DC: National Academy of Sciences 1974; pp 99-101. 
[29] Wapnir R. Zinc deficiency, malnutrition and the gastrointestinal tract. J Nutr 2000; 130:1388S-1392S

[30] Miller L, Krebs NF, Hambidge KM. A mathematical model of zinc absorption in humans as a function of dietary zinc and phytate. J Nutr 2007; 137:135-141

[31] Prasad AS. Impact of the discovery of human zinc deficiency on health. J Am Coll Nutr 2009; 28:257-265

[32] Giacconi R, Costarelli L, Piacenza F, et al. Main biomarkers associated with agerelated plasma zinc decrease and copper/zinc ration in healthy elderly from ZincAge study. Eur J Nutr 2017; 56:24572466

[33] Malavolta M, Piacenza F, Basso A, Giacconi R, Costarelli L and Mocchegiani E. Serum copper to zinc ratio: relationship with aging and health status. Mech Age Dev 2015; 15:93-100.

[34] Meunier N, Feillet-Coudray C, Rambeau $\mathrm{M}$, et al. Impact of micronutrient dietary intake and status on intestinal zinc absorption in late middle-aged men: the ZENITH study. Eur J Clin Nutr 2005; 59:S48-S52

[35] Willis MS, Monaghan SA, Miller ML, et al. Zinc-Induced Copper Deficiency: A Report of Three Cases Initially Recognized on Bone Marrow Examination. AJCP 2005;123:125-131

[36] Haase H, Mocchegiani E and Rink L. Correlation between zinc status and immune function in the elderly. Biogerontology 2006; 7:421-428.

[37] Penny ME. Zinc supplementation in public health. Ann Nutr Metab 2013; 62 Suppl 1: 31-42.

[38] Prasad AS, Beck FW, Bao B, et al. Zinc supplementation decreases incidence of infections in the elderly: effect of zinc on generation of cytokines and oxidative stress. Am J Clin Nutr 2007; 85: 837-844.

[39] Tuerk MJ, Fazel N. Zinc deficiency. Curr Opin Gastroenterol 2009; 25:136-143.

[40] Brown KH, Peerson JM, Rivera J, Allen LH. Effect of supplemental zinc on the growth and serum zinc concentrations of prepubertal children: a meta-analysis of randomized controlled trials. Am J Clin Nutr 2002; 75:1062-1071.

[41] Vavvas DG, Small KW, Awh CC, et al. $\mathrm{CFH}$ and ARMS2 genetic risk determines progression to neovascular age-related macular degeneration after antioxidant and zinc supplementation Proc Natl Acad Sci 2018;115(4):E696-E704.
[42] 1000 Genomes Project Consortium, Auton A, Brooks LD, et al. A global reference for human genetic variation. Nature.2015 ; 526(7571):68-74

[43] Day KJ, Adamski MM, Dordevia AJ and Murgia C. Genetic variations as modifying factors to dietary zinc requirements - a systematic review. Nutrients 2017; 9:148

[44] Costarelli L, Muti E, Malavolta M, et al. Distinctive modulation of inflammatory and metabolic parameters in relation to zinc nutritional status in adult overweight/obese subjects. J Nutr Biochem 2010; 21(5):432-437

[45] Giacconi R, Cipriano C, Muti E, et al. Novel -209A/G MT2A polymorphism in old patients with type 2 diabetes and atherosclerosis: relationship with inflammation (IL-6) and zinc. Biogerontology. 2005;6(6):407-13

[46] Raudenska M, Dvorakova V, Pacal L, et al. Levels of heavy metals and their binding protein metallothionein in type 2 diabetics with kidney disease. J Biochem Mol Toxicol 2017;31(6).

[47] Giacconi R, Caruso C, Malavolta M, et al. Pro-inflammatory genetic background and zinc status in old atherosclerotic subjects. Age Res Rev 2008; 7:306-316

[48] Kagi JH, Kojima Y. Chemistry and biochemistry of metallothionein. Experientia Suppl. 1987;52:25-61.

[49] Hennigar SR, Kelleher SL. Zinc networks: The cell-specific compartmentalization of zinc for specialized functions. Biol Chem.2012; 393: 565-78.

[50] Hara T, Takeda TA, Takagishi T, Fukue K, Kambe T, Fukada T. Physiological roles of zinc transporters: molecular and genetic importance in zinc homeostasis. J Physiol Sci 2017;67(2):283-301.

[51] Suzuki K, Koizumi S. Individual metal responsive elements of the human metallothionein-IIA gene independently mediate responses to various heavy metal signals. Ind Health 2000; 38: 87-90.

[52] Giacconi R, Costarelli L, Malavolta M, et al. Effect of ZIP2 Gln/Arg/Leu (rs2234632) polymorphism on zinc homeostasis and inflammatory response following zinc supplementation. Biofactors 2015; 41(6):414-23.

[53] Chan J, Merrifield ME, Soldatov A V., Stillman MJ. XAFS spectral analysis of the cadmium coordination geometry in cadmium thiolate clusters in metallothionein. Inorg Chem 2005; 44:4923-33. 
[54] Coyle P, Philcox JC, Carey LC, Rofe AM. Metallothionein: The multipurpose protein. Cell Mol Life Sci 2002; 59: 62747.

[55] Karin M, Eddy RL, Henry WM, Haley LL, Byers MG, Shows TB. Human metallothionein genes are clustered on chromosome 16. Proc Natl Acad Sci U. S. A.1984; 81: 5494-98.

[56] Klaassen CD, Liu J. Metallothionein transgenic and knock-out mouse models in the study of cadmium toxicity. J Toxicol Sci 1998; 23 Suppl 2: 97-102.

[57] Laukens D, Waeytens A, De Bleser P, Cuvelier C, De Vos M. Human metallothionein expression under normal and pathological conditions: mechanisms of gene regulation based on in silico promoter analysis. Crit Rev Eukaryot Gene Expr 2009; 19: 301-17.

[58] Skroch P, Buchman C, Karin M. Regulation of human and yeast metallothionein gene transcription by heavy metal ions. Prog Clin Biol Res 1993; 380: 113-28.

[59] Kim HG, Kim JY, Han EH, et al. Metallothionein-2A overexpression increases the expression of matrix metalloproteinase- 9 and invasion of breast cancer cells. FEBS Lett 2011; 585(2):4218

[60] Yang L, Li H, Yu T, et al. Polymorphisms in metallothionein-1 and -2 genes associated with the risk of type 2 diabetes mellitus and its complications. Am J Physiol Endocrinol Metab 2008; 294: E987-92.

[61] Cipriano C, Malavolta M, Costarelli L, et al. Polymorphisms in MT1a gene coding region are associated with longevity in Italian Central female population. Biogerontology 2006; 7: 357-65.

[62] Adams JN, Martelle SE, Raffield LM, et al. Analysis of advanced glycation end products in the DHS Mind Study J Diabetes Complications 2016; 30(2): 26268.

[63] Morahan JM, Yu B, Trent RJ, Pamphlett R. Genetic susceptibility to environmental toxicants in ALS. Am J Med Genet B Neuropsychiatr Genet 2007; 144: 885-90.

[64] Wang Y, Goodrich JM, Gillespie B, Werner R, Basu N, Franzblau A. An investigation of modifying effects of metallothionein single-nucleotide polymorphisms on the association between mercury exposure and biomarker levels Environ Health Perspect 2012; 120(4): 530-534

[65] Sun L, Zhang X, Kong Y, Yu L. [Effect of MT1M gene on the cell cycle and signaling pathway of Hep-G2]. Zhonghua Nan Ke Xue 2004; 10: 932-34.

[66] Hattori Y, Naito M, Satoh M, et al. Metallothionein MT2A A-5G polymorphism as a risk factor for chronic kidney disease and diabetes: Crosssectional and cohort studies. Toxicol Sci 2016; 152:181-93.

[67] Liang Q, Carlson EC, Donthi RV, Kralik PM, Shen X, Epstein PN. Overexpression of metallothionein reduces diabetic cardiomyopathy Diabetes 2002; 51: 17481.

[68] Kozarova R, Postadzhiyan A, Finkov B, Apostolova M. Association of copy number variations and single nucleotide polymorphisms in metallothionein genes with pathogenesis of diabetes and coronary artery disease. Atherosclerosis Supplements 2011; 12: 107.

[69] Giacconi R, Muti E, Malavolta M, et al. The +838 C/G MT2A polymorphism, metals, and the inflammatory/immune response in carotid artery stenosis in elderly people. Mol Med 2007; 13: 38895.

[70] Hidalgo J, Aschner M, Zatta P, Vašák M. Roles of the metallothionein family of proteins in the central nervous system. Brain Res Bull 2001; 55: 133-45.

[71] Quaife CJ, Findley SD, Erickson JC, et al. Induction of a New Metallothionein Isoform (MT-IV) Occurs during Differentiation of Stratified Squamous Epithelia. Biochemistry 1994; 33: 725059.

[72] Tío L, Villarreal L, Atrian S, Capdevila M. Functional differentiation in the mammalian metallothionein gene family. Metal binding features of mouse MT4 and comparison with its paralog MT1. J Biol Chem 2004; 279: 24403-13.

[73] Chen HI, Chiu YW, Hsu YK, Li WF, Chen YC, Chuang HY. The association of metallothionein-4 gene polymorphism and renal function in long-term lead-exposed workers. Biol Trace Elem Res 2010; 137: 55-62.

[74] Palmiter RD, Huang L. Efflux and compartmentalization of zinc by members of the SLC30 family of solute carriers. Pflugers Arch 2004; 447: 744-51.

[75] Haney CJ, Grass G, Franke S, Rensing C. New developments in the understanding of 
the cation diffusion facilitator family. $\mathrm{J}$ Ind Microbiol Biotechno 2005; 32: 21526.

[76] Lu M, Fu D. Structure of the zinc transporter YiiP. Science 2007; 317: 1746-48.

[77] Inoue K, Matsuda K, Itoh M, Kawaguchi $\mathrm{H}$, Tomoike $\mathrm{H}$, Aoyagi $\mathrm{T}$, et al. Osteopenia and male-specific sudden cardiac death in mice lacking a zinc transporter gene, Znt5. Hum Mol Genet 2002; 11:1775-84.

[78] Huang L, Kirschke CP, Gitschier J. Functional characterization of a novel mammalian zinc transporter, ZnT6. J Biol Chem 2002; 277: 26389-95.

[79] Kirschke CP, Huang L. ZnT7, a novel mammalian zinc transporter, accumulates zinc in the Golgi apparatus. J Biol Chem 2003; 278: 4096-4102.

[80] Leyva-Illades D, Chen P, Zogzas CE, et al. SLC30A10 Is a Cell Surface-Localized Manganese Efflux Transporter, and Parkinsonism-Causing Mutations Block Its Intracellular Trafficking and Efflux Activity. J Neurosci 2014; 34: 14079-95.

[81] Helston RM, Phillips SR, McKay JA, Jackson KA, Mathers JC, Ford D. Zinc Transporters in the Mouse Placenta Show a Coordinated Regulatory Response to Changes in Dietary Zinc Intake. Placenta 2007; 28: 437-44.

[82] Andrews GK, Wang H, Dey SK, Palmiter RD. Mouse zinc transporter 1 gene provides an essential function during early embryonic development. Genesis 2004; 40: 74-81.

[83] Langmade SJ, Ravindra R, Daniels PJ, Andrews GK. The transcription factor MTF-1 mediates metal regulation of the mouse ZnT1 gene. J Biol Chem 2000; 275: 34803-9.

[84] Cragg RA, Phillips SR, Piper JM, et al. Homeostatic regulation of zinc transporters in the human small intestine by dietary zinc supplementation. Gut 2005; 54: 469-78.

[85] McCormick NH, Lee S, Hennigar SR, Kelleher SL. ZnT4 ( SLC30A4)-null ("lethal milk") mice have defects in mammary gland secretion and hallmarks of precocious involution during lactation. Am J Physiol Regul Integr Comp Physiol 2016; 310: R33-40.

[86] Kambe T, Narita H, Yamaguchi-Iwai Y, et al. Cloning and characterization of a novel mammalian zinc transporter, zinc transporter 5, abundantly expressed in pancreatic $\beta$ cells. J Biol Chem 2002; 277: 19049-55.

[87] Huang L, Yan YY, Kirschke CP, Gertz ER, Lloyd KKC. Znt7 (Slc30a7)-deficient mice display reduced body zinc status and body fat accumulation. J Biol Chem 2007; 282: 37053-63.

[88] Pound LD, Sarkar SA, Benninger RKP, et al. Deletion of the mouse Slc30a8 gene encoding zinc transporter-8 results in impaired insulin secretion. Biochem $\mathrm{J}$ 2009; 421: 371-76.

[89] Wijesekara N, Dai FF, Hardy AB, et al. Beta cell-specific Znt8 deletion in mice causes marked defects in insulin processing, crystallisation and secretion. Diabetologia 2010; 53: 1656-68.

[90] Wang X, Chorley BN, Pittman GS, et al. Genetic variation and antioxidant response gene expression in the bronchial airway epithelium of smokers at risk for lung cancer. PLoS One 2010; 5.

[91] Cuadrado A, Manda G, Hassan A, et al. Transcription Factor NRF2 as a Therapeutic Target for Chronic Diseases: A Systems Medicine Approach. Pharmacol Rev 2018; 70(2):348-383.

[92] Adlard PA, Parncutt JM, Finkelstein DI, Bush AI. Cognitive Loss in Zinc Transporter-3 Knock-Out Mice: A Phenocopy for the Synaptic and Memory Deficits of Alzheimer's Disease? J Neurosci 2010; 30: 1631-36.

[93] Sladek R, Rocheleau G, Rung J, et al. A genome-wide association study identifies novel risk loci for type 2 diabetes. Nature 2007; 445: 881-85.

[94] Saxena R, Voight BF, Lyssenko V, et al. Genome-wide association analysis identifies loci for type 2 diabetes and triglyceride levels. Science 2007; 316: 1331-36.

[95] Scott LJ, Mohlke KL, Bonnycastle LL, et al. A genome-wide association study of type 2 diabetes in Finns detects multiple susceptibility variants. Science $2007 ; 316$ : 1341-45.

[96] Votsi C, Toufexis C, Michailidou K, et al. Type 2 diabetes susceptibility in the Greek-Cypriot population: Replication of associations with TCF7L2, FTO, HHEX, SLC30A8 and IGF2BP2 polymorphisms. Genes 2017; 8 .

[97] Omori S, Tanaka Y, Takahashi A, et al. Association of CDKAL1, IGF2BP2, CDKN2A/B, HHEX, SLC30A8, and KCNJ11 with susceptibility to type 2 
diabetes in a Japanese population. Diabetes 2008; 57: 791-95.

[98] Ng MCY, Park KS, Oh B, et al. Implication of genetic variants near TCF7L2, SLC30A8, HHEX, CDKAL1, CDKN2A/B, IGF2BP2, and FTO in type 2 diabetes and obesity in 6,719 Asians. Diabetes 2008; 57: 2226-33.

[99] Sanghera DK, Ortega L, Han S, et al. Impact of nine common type 2 diabetes risk polymorphisms in Asian Indian Sikhs: PPARG2 (Pro12Ala), IGF2BP2, TCF7L2 and FTO variants confer a significant risk. BMC Med Genet 2008; 9: 59.

[100] Xiang J, Li XY, Xu M, et al. Zinc transporter-8 gene (SLC30A8) is associated with type 2 diabetes in Chinese. J Clin Endocrinol Metab 2008; 93: 410712.

[101] Wu Y, Li H, Loos RJF, et al. Common variants in CDKAL1, CDKN2A/B, IGF2BP2, SLC30A8, and HHEX/IDE genes are associated with type 2 diabetes and impaired fasting glucose in a Chinese Han population. Diabetes 2008; 57: 283442.

[102] Lee Y-H, Kang ES, Kim SH, et al. Association between polymorphisms in SLC30A8, HHEX, CDKN2A/B, IGF2BP2, FTO, WFS1, CDKAL1, KCNQ1 and type 2 diabetes in the Korean population. J Hum Genet 2008; 53: 991.

[103] Rong R, Hanson RL, Ortiz D, et al. Association analysis of variation in/near FT0, CDKAL1, SLC30A8, HHEX, EXT2, IGF2BP2, LOC387761, and CDKN2B with type 2 diabetes and related quantitative traits in pima indians. Diabetes 2009; 58: 478-88.

[104] Gan W, Walters RG, Holmes M V, et al. Evaluation of type 2 diabetes genetic risk variants in Chinese adults: findings from 93,000 individuals from the China Kadoorie Biobank. Diabetologia 2016; 59: 1446-57.

[105] Huang Q, Yin JY, Dai XP, et al. Association analysis of SLC30A8 rs13266634 and rs16889462 polymorphisms with type 2 diabetes mellitus and repaglinide response in Chinese patients. Eur J Clin Pharmacol 2010; 66: 1207-15.

[106] Sikhayeva N, Iskakova A, Saigi-Morgui N, Zholdybaeva E, Eap C Bin, Ramanculov E. Association between 28 single nucleotide polymorphisms and type 2 diabetes mellitus in the Kazakh population: A case-control study. BMC Med Genet 2017; 18.

[107] Phani NM, Adhikari P, Nagri SK, D'Souza SC, Satyamoorthy K, Rai PS. Replication and Relevance of Multiple Susceptibility Loci Discovered from Genome Wide Association Studies for Type 2 Diabetes in an Indian Population PLoS One. 2016;Jun 16;11(6):e0157364.

[108] Nikitin AG, Potapov VY, Brovkina OI, et al. Association of polymorphic markers of genes FTO, KCNJ11, CDKAL1, SLC30A8, and CDKN2B with type 2 diabetes mellitus in the Russian population. PeerJ 2017; 5:e3414.

[109] Kifagi C, Makni K, Boudawara M, et al. Association of genetic variations in TCF7L2, SLC30A8, HHEX, LOC387761, and EXT2 with Type 2 diabetes mellitus in Tunisia. Genet Test Mol Biomarkers 2011; 15: 399-405.

[110] Gamboa-Meléndez MA, Huerta-Chagoya A, Moreno-Macías H, et al. Contribution of common genetic variation to the risk of type 2 diabetes in the Mexican Mestizo population. Diabetes 2012; 61: 3314-21.

[111] Kulkarni H, Mamtani M, Peralta JM, et al. Lack of Association between SLC30A8 Variants and Type 2 Diabetes in Mexican American Families. J Diabetes Res 2016; 2016:6463214.

[112] Lara-Riegos JC, Ortiz-López MG, PeñaEspinoza BI, et al. Diabetes susceptibility in Mayas: Evidence for the involvement of polymorphisms in HHEX, HNF4 $\alpha$, KCNJ11, PPAR $\gamma, \quad$ CDKN2A/2B, SLC30A8, CDC123/CAMK1D, TCF7L2, ABCA1 and SLC16A11 genes. Gene 2015; 565: 68-75.

[113] Lewis JP, Palmer ND, Hicks PJ, et al. Association analysis in african americans of european-derived type 2 diabetes single nucleotide polymorphisms from wholegenome association studies. Diabetes 2008; 57(8): 2220-2225.

[114] Palmer ND, Goodarzi MO, Langefeld CD, et al. Quantitative trait analysis of type 2 diabetes susceptibility loci identified from whole genome association studies in the Insulin Resistance Atherosclerosis Family Study. Diabetes 2008;57(4):1093-100.

[115] O'Beirne SL, Salit J, Rodriguez-Flores JL, et al. Type 2 diabetes risk allele loci in the Qatari population. PLoS One 2016; 11 :e0156834

[116] Faghih H, Khatami SR, Azarpira N, Foroughmand AM. SLC30A8 gene polymorphism (rs13266634 C/T) and type 
2 diabetes mellitus in south Iranian population. Mol Biol Rep 2014; 41: 270915.

[117] Jing YL, Sun QM, Bi Y, Shen SM, Zhu DL. SLC30A8 polymorphism and type 2 diabetes risk: evidence from 27 study groups. Nutr Metab Cardiovasc Dis 2011; 21: 398-405.

[118] Fan M, Li W, Wang L, et al. Association of SLC30A8 gene polymorphism with type 2 diabetes, evidence from 46 studies: a meta-analysis. Endocrine 2016; 53: 38194.

[119] Chimienti F, Devergnas S, Favier A, Seve M. Identification and cloning of a betacell-specific zinc transporter, ZnT-8, localized into insulin secretory granules. Diabetes 2004; 53: 2330-37.

[120] Kirchhoff K, Machicao F, Haupt A, et al. Polymorphisms in the TCF7L2, CDKAL1 and SLC30A8 genes are associated with impaired proinsulin conversion. Diabetologia 2008; 51: 597-601.

[121] Stančáková A, Kuulasmaa T, Paananen J, et al. Association of 18 confirmed susceptibility loci for type 2 diabetes with indices of insulin release, proinsulin conversion, and insulin sensitivity in 5,327 nondiabetic Finnish men. Diabetes 2009; 58: 2129-36.

[122] Staiger H, Machicao F, Stefan N, et al. Polymorphisms within novel risk loci for type 2 diabetes determine beta-cell function. PLoS One 2007; 2: e832.

[123] Boesgaard TW, Žilinskaite J, Vänttinen $\mathrm{M}$, et al. The common SLC30A8 Arg325Trp variant is associated with reduced first-phase insulin release in 846 non-diabetic offspring of type 2 diabetes patients - The EUGENE2 study. Diabetologia 2008; 51: 816-20.

[124] Merriman C, Huang Q, Rutter GA, Fu D. Lipid-tuned zinc transport activity of human ZnT8 protein correlates with risk for type-2 diabetes. J Biol Chem. 2016; 291: 26950-57.

[125] Gohlke H, Ferrari U, Koczwara K, Bonifacio E, Illig $\mathrm{T}$, Ziegler AG. SLC30A8 (ZnT8) polymorphism is associated with young age at type 1 diabetes onset. Rev Diabet Stud 2008; 5: 25-27.

[126] Wenzlau JM, Liu Y, Yu L, et al. A common nonsynonymous single nucleotide polymorphism in the slc30a8 gene determines znt8 autoantibody specificity in type 1 diabetes. Diabetes 2008; Oct; 57(10): 2693-2697
[127] Kawasaki E, Uga M, Nakamura K, et al. Association between anti-ZnT8 autoantibody specificities and SLC30A8 Arg325Trp variant in Japanese patients with type 1 diabetes. Diabetologia 2008; 51: 2299-2302.

[128] Sousa AGP, Lopes NH, Hueb WA, Krieger JE, Pereira AC. Genetic Variants of Diabetes Risk and Incident Cardiovascular Events in Chronic Coronary Artery Disease. PLoS ONE 2011; 6(1): e16341. https://doi.org/10.1371/journal.pone.0016 341

[129] Pineda-Tenor D, Micheloud D, Berenguer $\mathrm{J}$, et al. SLC30A8 rs13266634 polymorphism is related to a favorable cardiometabolic lipid profile in HIV/hepatitis C virus-coinfected patients. AIDS 2014; 28: 1325-32.

[130] Sprouse C, Gordish-Dressman H, Orkunoglu-Suer EF, et al. SLC30A8 nonsynonymous Variant is associated with recovery following exercise and skeletal muscle size and strength. Diabetes 2014; Jan; 63(1): 363-368.

[131] Dupuis J, Langenberg C, Prokopenko I, et al. New genetic loci implicated in fasting glucose homeostasis and their impact on type 2 diabetes risk. Nat Genet 2010; 42: 105-16.

[132] Lin Y, Li P, Cai L, et al. Association study of genetic variants in eight genes/loci with type 2 diabetes in a Han Chinese population. BMC Med Genet 2010; 11: 97

[133] Hu C, Zhang R, Wang C, et al. Variants from GIPR, TCF7L2, DGKB, MADD, CRY2, GLIS3, PROX1, SLC30A8 and IGF1 are associated with glucose metabolism in the chinese. PLoS One 2010; 5: e15542

[134] Seman NA, Mohamud WNW, Östenson C-G, Brismar K, Gu HF. Increased DNA methylation of the SLC30A8 gene promoter is associated with type 2 diabetes in a Malay population. Clin Epigenetics 2015;7:30.

[135] Xu J, Wang J, Chen B. SLC30A8 (ZnT8) variations and type 2 diabetes in the Chinese Han population. Genet Mol Res 2012;11(2):1592-8.

[136] Horikawa Y, Miyake K, Yasuda K, et al. Replication of genome-wide association studies of type 2 diabetes susceptibility in Japan. J Clin Endocrinol Metab 2008; 93: 3136-41.

[137] Xu M, Bi Y, Xu Y, et al. Combined Effects of 19 Common Variations on Type 
2 Diabetes in Chinese: Results from Two Community-Based Studies. PLoS One 2010; 5: e14022.

[138] Gomes KFB, Semzezem C, Batista R, et al. Importance of zinc transporter 8 autoantibody in the diagnosis of type 1 diabetes in Latin Americans. Sci Rep 2017; 7: 2017

[139] Wang X, Li W, Ma L, et al. Investigation of miRNA-binding site variants and risk of gestational diabetes mellitus in Chinese pregnant women. Acta Diabetol 2017; 54(3):309-316.

[140] Rosta K, Al-Aissa Z, Hadarits O, et al. Association study with 77 SNPs confirms the robust role for the rs $10830963 / \mathrm{G}$ of MTNR1B variant and identifies two novel associations in gestational diabetes mellitus development. PLoS One 2017; $12: \mathrm{e} 0169781$

[141] Teleginski A, Welter M, Frigeri HR, et al. Leptin (rs7799039) and solute carrier family 30 zinc transporter (rs13266634) polymorphisms in Euro-Brazilian pregnant women with gestational diabetes. Genet Mol Res 2017; 16.

[142] Prasad AS, Halsted JA and Nadimi M. Syndrome of iron deficiency anaemia, hepatosplenomegaly, hypogonadism, dwarfism and geophagia. Am J Med 1961; 31:532-546

[143] Bonaventura P, Benedetti G, Albarede F and Miossec P. Zinc and its role in immunity and inflammation. Autoimm rev 2015; 14:277-285

[144] Fraker PJ and Telford WG. A reappraisal of the role of zinc in life and death decisions of cells. Proc Soc Exp Biol Med 1997; 215:229-236

[145] Mocchegiani E, Costarelli L, Giacconi R, et al. Micronutrient-gene interactions related to inflammatory/immune response and antioxidant activity in ageing and inflammation. A systematic review. Mech Age Dev 2014; 136-137:29-49

[146] Prasad AS. Zinc in human health: effect of zinc on immune cells. Mol Med 2008; 14:5-6

[147] Chiricolo M, Musa AR, Monti D, Zannotti $M$ and Franceschi C. Enhanced DNA repair in lymphocytes of Down syndrome patients: the influence of zinc nutritional supplementation. Mut Res 1993; 295:105111

[148] Andree KB, Kim J, Kirschke CP, et al. Investigation of lymphocyte gene expression for use as biomarkers for zinc state in humans. J Nutr 2004; 134:17161723

[149] Sanna A, Firinu D, Zavattari P and Valera P. Zinc status and autoimmunity: A systematic review and meta-analysis. Nutrients 2018; 10:68

[150] Mariani E, Neri, S, Cattini L, et al. Effect of zinc supplementation on plasma IL-6 and MCP-1 production and NK function in healthy elderly: interactive influence of +647 MTA1a and -174 IL-6 polymorphic alleles. Exp Geron 2008; 43(5):462-471 corretto anno uscita 2008

[151] Mocchegiani E, Malavolta M, Lattanzio F, et al. $\mathrm{Cu}$ to $\mathrm{Zn}$ ration, physical activity, disability and mortality risk in older elderly (ilSIRENT study). Age 2012; 34:539-552

[152] Kury S, Dreno B, Bezieau S, et al. Identification of a SLC39A\$, a gene involved in acrodermatitis enterpathica. Nature Genetics 2002; 31:239-240

[153] Rink L and Kirchner H. Zinc-altered immune function and cytokine production. J Nutr 2000; 130:1407S-1411S

[154] Giacconi R, Costarelli L, Malavolta M, et al. Association among 1267 A/G HSP702, -308 G/A TNF-a polymorphisms and pro-inflammatory plasma mediators in old ZincAge population. Biogerontology 2014; 15:65-79

[155] Wong CP, Rinaldi NA and Ho E. Zinc deficiency enhanced inflammatory response by increasing immune cell activation and inducing IL promoter demethylation. Mol Nutr Food Res 2015; 59:991-999

[156] Borghaei RC, Gorski G, Seutter S, Chun J, Khaselov N and Scianni S. Zinc binding protein-89 (ZBP-89) cooperates with NF$\mathrm{kB}$ to regulate expression of matrix metalloproteinases (MMPs) in response to inflammatory cytokines. Biochem Biophys Res Comm 2016; 471:503-509

[157] Munhoz FBA, Godoy-Santos AL and Santos MCLG. MMP-3 polymorphism: Genetic marker in pathological processes (Review). Mol Med Rep 2010; 3:735-740

[158] Mocchegiani E, Basso A, Giacconi R, et al. Diet (zinc)-gene interaction related to inflammatory/immune response in ageing: possibility link with frailty syndrome? Biogerontology 2010; 11:589-595

[159] Global Burden of Diseases (GBD) 2016 Risk Factors Collaborators. Global, regional, and national comparative risk assessment of 84 behavioural, environmental and occupational, and 
metabolic risks or clusters of risks, 19902016: a systematic analysis for the Global Burden of Disease Study 2016. Lancet 2017;390(10100):1345-1422.

[160] Alberti K.G.M.M., Zimmet P. and J. Shaw "Metabolic syndrome - a new world-wide definition. A Consensus Statement from the International Diabetes Federation" Diabet Med 2006; 23, 469-480

[161] Alberti KG, Eckel RH, Grundy SM, et al. Harmonizing the metabolic syndrome: a joint interim statement of the International Diabetes Federation Task Force on Epidemiology and Prevention; National Heart, Lung, and Blood Institute; American Heart Association; World Heart Federation; International Atherosclerosis Society; and International Association for the Study of Obesity. Circulation 2009; 120(16):1640-5.

[162] Nolan PB, Carrick-Ranson G, Stinear JW, Reading SA, Dalleck LC. Prevalence of metabolic syndrome and metabolic syndrome components in young adults: A pooled analysis. Prev Med Rep. 2017;7:211-215

[163] Henneman P, Aulchenko YS, Frants RR, van Dijk KW, Oostra BA, van Duijn CM. Prevalence and heritability of the metabolic syndrome and its individual components in a Dutch isolate: the Erasmus Rucphen Family study. J Med Genet 2008; 45: 572-577.

[164] Bellia A, Giardina E, Lauro D, et al. 'The Linosa Study': epidemiological and heritability data of the metabolic syndrome in a Caucasian genetic isolate. Nutr Metab Cardiovasc Dis 2009; 19: 455-461.

[165] Musani S, Martin LJ, Woo JG, Olivier M, Gurka MJ, DeBoer MD. Heritability of the Severity of the Metabolic Syndrome in Whites and Blacks in 3 Large Cohorts. Circ Cardiovasc Genet 2017 Apr; 10(2)

[166] Povel CM, Boer JM, Reiling E, Feskens EJ. Genetic variants and the metabolic syndrome: a systematic review. Obes Rev. 201;12(11):952-67.

[167] de Luis DA., Pacheco D, Izaola O, Terroba MC, Cuellar L, Cabezas G, Micronutrient status in morbidly obese women before bariatric surgery. Surg Obes Relat Dis 2013; 9(2):323-327

[168] Suliburska J, Cofta S, Gajewska E, et al. The evaluation of selected serum mineral concentrations and their association with insulin resistance in obese adolescents.
Eur Rev Med Pharmacol Sci 2013;17(17):2396-2400

[169] Ferro FED, de Sousa Lima VB, Mello Soares NR, Franciscato Cozzolino SM, Nascimento Marreiro DD. Biomarkers of metabolic syndrome and its relationship with the zinc nutritional status in obese women. Nutr Hosp 2011;26(3):650-654

[170] Błazewicz A, Klatka M, Astel A, Partyka M, Kocjan R. Differences in trace metal concentrations (Co, $\mathrm{Cu}, \mathrm{Fe}, \mathrm{Mn}, \mathrm{Zn}, \mathrm{Cd}$, and $\mathrm{Ni}$ ) in whole blood, plasma, and urine of obese and nonobese children. Biol Trace Elem Res 2013; 155(2):190-200

[171] Ranasinghe P, Wathurapatha WS, Ishara $\mathrm{MH}$, et al. Effects of Zinc supplementation on serum lipids: a systematic review and meta-analysis. Nutr Metab 2015; 12:26.

[172] Olechnowicz J, Tinkov A, Skalny A, Suliburska J. Zinc status is associated with inflammation, oxidative stress, lipid, and glucose metabolism. J Physiol Sci 2018 Jan; 68(1):19-31

[173] Jansen, J, Rosenkranz, E, Overbeck, S, et al. Disturbed zinc homeostasis in diabetic patients by in vitro and in vivo analysis of insulinomimetic activity of zinc. The Journal of nutritional biochemistry 2012; 23(11), 1458-1466.

[174] Hara T, Takeda TA, Takagishi T, Fukue K, Kambe T, Fukada TJ. Physiological roles of zinc transporters: molecular and genetic importance in zinc homeostasis. J Physiol Sci 2017; 67(2):283-301

[175] Wenzlau, JM., Hutton, JC. Novel diabetes autoantibodies and prediction of type 1 diabetes. Curr Diab Rep 2013; 13(5), 608615.

[176] Gohlke H, Ferrari U, Koczwara K, et al. SLC30A8 (ZnT8) Polymorphism is Associated with Young Age at Type 1 Diabetes Onset. Rev Diabet Stud 2008; 5(1): 25-7.

[177] Xu, K., Zha, M., Wu, X., et al. Association between rs13266634 C/T polymorphisms of solute carrier family 30 member 8 (SLC30A8) and type 2 diabetes, impaired glucose tolerance, type 1 diabetes - a meta-analysis. Diabetes research and clinical practice 2011; 91(2), 195-202.

[178] Howson J.M.M., Krause S, Stevens H, et al. Genetic association of zinc transporter 8 (ZnT8) autoantibodies in type 1 diabetes cases. Diabetologia 2012; 55(7), 19781984. 
[179] Kawasaki E. ZnT8 and type 1 diabetes. Endocrine journal 2012, 59(7), 531-537.

[180] Araujo, D. B., Skärstrand, H., Barone, B., et al. Zinc transporter 8 autoantibodies in patients with type 1 diabetes from a multiethnic population and their first degree relatives. Arquivos Brasileiros de Endocrinologia \& Metabologia 2014; 58(7), 737-743

[181] Sladek R, Rocheleau G, Rung J, et al. A genome-wide association study identifies novel risk loci for type 2 diabetes. Nature 2007; 445(7130): 881-5

[182] Shan Z, Bao W, Zhang Y, et al. Interactions between zinc transporter-8 gene (SLC30A8) and plasma zinc concentrations for impaired glucose regulation and type 2 diabetes. Diabetes 2014; 63(5), 1796-1803.

[183] Rutter, G.A. \& Chimienti, F. SLC30A8 mutations in type 2 diabetes. Diabetologia 2015; 58(1), 31-36.

[184] Myers SA.. Zinc transporters and zinc signaling: new insights into their role in type 2 diabetes. International journal of endocrinology, 2015. Int $\mathrm{J}$ Endocrinol 2015:167503.

[185] Maret, W. Zinc in pancreatic islet biology, insulin sensitivity, and diabetes. Preventive nutrition and food science 2017; 22(1), 1.

[186] Gu HF. Genetic, epigenetic and biological effects of zinc transporter (SLC30A8) in type 1 and type 2 diabetes. Current Diabetes Reviews 2017; 13(2), 132-140.

[187] Delli A.J, Vaziri-Sani F, Lindblad B, et al. Zinc transporter 8 autoantibodies and their association with SLC30A8 and HLA-DQ genes differ between immigrant and Swedish patients with newly diagnosed type 1 diabetes in the Better Diabetes Diagnosis study. Diabetes 2012; 61(10), 2556-2564.

[188] Johnson K., Wong R, Barriga KJ, et al. rs11203203 is associated with type 1 diabetes risk in population pre- screened for high- risk HLA- DR, DQ genotypes. Pediatric Diabetes 2012; 13(8), 611-615.

[189] Norouzi, S, Adulcikas, J, Sohal, SS, Myers S. Zinc transporters and insulin resistance: therapeutic implications for type 2 diabetes and metabolic disease. $\mathrm{J}$ Biomed Sci 2017; 24(1), 87.

[190] Maruthur NM., Clark JM., Fu M., Kao WL, Shuldiner AR. (). Effect of zinc supplementation on insulin secretion: interaction between zinc and SLC30A8 genotype in Old Order Amish. Diabetologia 2015; 58(2), 295-303.

[191] Billings LK, Jablonski KA., Ackerman RJ, et al. The influence of rare genetic variation in slc30a8 on diabetes incidence and $\beta$-cell function. $\mathrm{J}$ Clin Endocrinol Metab 2014; 99(5), E926-E930.

[192] Kanoni S, Nettleton JA., Hivert MF, et al. Total zinc intake may modify the glucoseraising effect of a zinc transporter (SLC30A8) variant: a 14-cohort metaanalysis. Diabetes 2011; 60(9), 24072416.

[193] Xu J, Wang J, Chen B. SLC30A8 (ZnT8) variations and type 2 diabetes in the Chinese Han population. Genet Mol Res 2012; 11(2), 1592-1598

[194] Lin Y, Li P, Cai L, et al. Association study of genetic variants in eight genes/loci with type 2 diabetes in a Han Chinese population. BMC Medical Genetics 2010; 11(1), 97

[195] Rees SD, Hydrie MZI, O'Hare JP, et al. Effects of 16 genetic variants on fasting glucose and type 2 diabetes in South Asians: ADCY5 and GLIS3 variants may predispose to type 2 diabetes. PloS one 2011; 6(9), e24710.

[196] Horikawa Y, Miyake K., Yasuda K, et al. Replication of genome-wide association studies of type 2 diabetes susceptibility in Japan. J Clin Endocrinol Metab 2008; 93(8), 3136-3141.

[197] Seman NA., Mohamud WNW, Östenson $\mathrm{CG}$, Brismar K, \& Gu HF. Increased DNA methylation of the SLC30A8 gene promoter is associated with type 2 diabetes in a Malay population. Clinical epigenetics 2015; 7(1), 30.

[198] Flannick J, Thorleifsson G, Beer NL, et al. Loss-of-function mutations in SLC30A8 protect against type 2 diabetes. Nat Genet 2014, 46(4), 357-363

[199] Mirhafez SR, Avan A, Pasdar A, et al. Zinc Finger 259 Gene Polymorphism rs964184 is Associated with Serum Triglyceride Levels and Metabolic Syndrome. Int J Mol Cell Med Winter 2016; Vol 5 No 112

[200] Aung LH, Yin RX, Wu DF, et al. Association of the variants in the BUD13ZNF259 genes and the risk of hyperlipidaemia. Journal of cellular and molecular medicine 2014;18:1417-28.

[201] Braun TR,. Been LF, Singhal A, et al. A Replication Study of GWAS-Derived Lipid Genes in Asian Indians: The Chromosomal Region 11q23.3 Harbors 
Loci Contributing to Triglycerides. PLOS ONE 2012; 7(5): e37056.

[202] Wu Y, Yu S, Wang S, et al. Zinc Finger Protein 259 (ZNF259) Polymorphisms are Associated with the Risk of Metabolic Syndrome in a Han Chinese Population. Clin Lab 2015; 61(5-6):615-21

[203] Ueyama C, Horibe H, Yamase Y, et al. FURIN and ZPR1 polymorphisms with metabolic syndrome. Biomed Rep; 3(5): 641-647.

[204] Comuzzie AG, Cole SA, Laston SL, et al. Novel genetic loci identified for the pathophysiology of childhood obesity in the Hispanic population. PLoS One 2012; 7(12):e51954. 